\title{
LOS SISTEMAS DE PROTECGIÓN DE DERECHOS HUMANOS DE LOS PAÍSES DEL SUR: UNA MIRADA A LAS INTERACCIONES ENTRE MULTILATERALISMO GLOBAL Y REGIONAL
}

\author{
Delphine Alles \\ Clara Egger
}

Consagrados por la Declaración de Viena de 1993 como norma de referencia en todos los continentes, promovidos en las principales organizaciones multilaterales mundiales y regionales, los derechos humanos ocupan una posición de hegemonía ideológica. ${ }^{1}$ La idea según la cual ciertos derechos, inherentes a la condición humana, pertenecen por igual a cada individuo ya no es cuestionable. De los 193 Estados miembros de la Asamblea General de Naciones Unidas, 160 han firmado uno o varios tratados, cartas, convenciones o declaraciones cuyo objeto principal es la protección de los derechos humanos en el marco global o regional. ${ }^{2}$ La imposición geográfica o cultural fuera de Norteamérica y

${ }^{1}$ Jack Donnelly, "The Relative Universality of Human Rights”, Human Rights Quarterly, vol. 29, núm. 2, 2007, p. 282.

${ }^{2}$ Aquí el análisis se concentra en los textos regionales específicamente dedicados al cuidado de los derechos humanos, en referencia a los instrumentos globales siguientes: la Declaración Universal de los Derechos Humanos (1948), el Pacto Internacional de Derechos Civiles y Políticos (1966), El Pacto Internacional de Derechos Económicos, Sociales y Culturales (1966) y sus protocolos adicionales, y la Declaración de Viena (1993). No se tratarán las disposiciones sobre los derechos humanos presentes en varios acuerdos regionales de libre comercio, que sobrepasan el marco de esta investigación. Cada uno de los textos mencionados en este artículo tiene una referencia directa a las cartas, convenciones y tratados internacionales relativos a los derechos humanos. Para un análisis 
Europa Occidental, por lo tanto, ya no se presenta como factor de rechazo de la noción de derechos universales.

Este universalismo conceptual, ${ }^{3}$ sin embargo, debe analizarse con base en la multiplicación de textos relativos a la protección de los derechos humanos, que la Asamblea General de la onu alentó desde la década de 1970 mediante disposiciones políticas regionales. Aunque la noción de derechos humanos se trate como referencia común, es objeto de reinterpretaciones y de medidas de protección diversas que sugieren una relativización, particularmente cuando los textos se adoptan en ambientes a priori poco respetuosos de tales principios. ${ }^{4}$ Los difusos contornos de los textos, tanto desde el punto de vista de su sustancia como del de su puesta en marcha, favorecen, en efecto, la adhesión de un mayor número de países. Por lo tanto, es posible presenciar la proliferación de textos acompañados de mecanismos de control, sin que éstos traigan consigo un sistema legal efectivo. ${ }^{5}$

Estos textos y sus evoluciones dan cuenta de un movimiento doble de universalización conceptual de largo plazo y de regionalización más coyuntural, que se ha podido asimilar a la neutralización de los principios universales a escala regional. Así, en derecho y en ciencia política, la mayoría de los trabajos convergen y consideran que la expansión hacia el "Sur" del reconocimiento de derechos humanos vendría acompañada de la dilución y diferenciación según las especificidades políticas y culturales que pretendían conservar. ${ }^{6}$ Esta constatación es poco válida,

detallado de su contenido y de los mecanismos de su puesta en marcha, véase Office of the High Commissioner for Human Rights y International Bar Association, "Chapter 3. The Major Regional Human Rights Instruments and the Mechanisms for Their Implementation", en Human Rights in the Administration of Justice: A Manual on Human Rights for Judges, Prosecutors and Lawyers, Nueva York, Naciones Unidas, 2003, pp. 71-111.

${ }^{3}$ Jack Donnelly, op. cit.

${ }^{4}$ Loc. cit.

${ }^{5}$ Beth A. Simmons, Mobilizing for Human Rights: International Law in Domestic Politics, Cambridge, University Press, 2009.

${ }^{6}$ Véase por ejemplo Simonne Wegmann, "Regional Human Rights Systems: a Comparative Analysis", Green Lab, núm. 1, Geneva Laboratory of Political Science, 2011; Jack Donnelly, "International Human Rights: a Regime Analysis", 
pues la Declaración Americana de los Derechos y Deberes del Hombre se adoptó en 1948, incluso antes que la Declaración Universal de los Derechos Humanos (DUDH), lo que de entrada debilita la idea de una circulación exclusivamente caracterizada por una dinámica Norte-Sur. Las lagunas que existen en materia de protección de los derechos humanos en los países del "Norte" contribuyen, además, a alejar la idea según la cual estos últimos construirían un modelo mejor logrado para los del "Sur". 7

Así, este artículo se aleja de una lectura minimalista para desarrollar la idea de que la diversificación refleja, antes que nada, una apropiación de las normas globales para los distintos conjuntos regionales. Por esta razón, decidimos centrar el análisis en las regiones reunidas bajo el apelativo de "Sur", es decir, fuera de Europa, Estados Unidos y Canadá, afirmando siempre la pluralidad de esta noción. Nuestro objetivo es centrar el estudio en los instrumentos elaborados fuera de los contextos que dominaron el surgimiento de las normas en materia de protección de derechos humanos, en particular la DUDH. El trabajo, por lo tanto, se centra en los textos adoptados paralela o ulteriormente a la DUDH, en contextos culturales y políticos diferentes: Declaración Americana de los Derechos y Deberes del Hombre (1948), la Convención Americana sobre Derechos Humanos (1969), ${ }^{8}$ la

International Organization, vol. 40, núm.3, 1986, pp. 599-642; Jacques Donnelly, op. cit.

${ }^{7}$ Para no tomar más que un ejemplo, el Consejo de los Derechos Humanos de Naciones Unidas y organizaciones no gubernamentales de protección de los derechos han denunciado recientemente las prácticas de vigilancia electrónica de Estados Unidos. Cf. Human Right Watch, http:/ / www.hrw.org/fr/news / 2014/03/ 12/etats-unis-les-pratiques-de-surveillance-electronique-violent-les-droits-humains consultado el 12 de abril de 2015. Para un balance crítico de la aplicación de la Convención Europea de los Derechos Humanos, véase Steven Greer, The European Convention on Human Rights: Achievements, Problems and Prospects, Cambridge, Cambridge University Press, 2006.

${ }^{8}$ Estos dos primeros textos se adoptaron en el marco de la Organización de Estados Americanos, que comprende a Estados Unidos y Canadá. Sin embargo, optamos por incluirlos en este estudio, por una parte, porque la gran mayoría de los miembros de la oEA (a los cuales rige la Declaración de 1948) son latinoamericanos o caribeños, y por otra, porque los dos Estados norteamericanos no firma- 
Carta Africana de Derechos Humanos y de los Pueblos (1981), la Declaración de los Derechos Humanos en el Islam (1990), las dos versiones de la Carta Árabe de Derechos Humanos (1994 y 2004) y la Declaración de Derechos Humanos de la Asociación de Naciones del Sudeste Asiático (ASEAn, por sus siglas en inglés) (2012).

Este estudio propone examinar la siguiente pregunta: ¿contribuyen las dinámicas de interacción normativas entre instrumentos regionales y globales a difundir o redefinir normas globales, en aras de los intercambios y la circulación entre actores del Sur y del Norte? Analizar esas dinámicas implica dotarse de herramientas teóricas que puedan dar cuenta de la diversidad de los canales de circulación y de los actores involucrados en tales interacciones. Se evocarán en particular dos niveles de análisis: el interestatal (los intercambios, acuerdos y estrategias de los Estados signatarios) y el de los órganos de control de los textos. Se trata, por lo tanto, de presentar a los del "Sur" como actores de la difusión de normas en materia de protección de los derechos humanos en la escena mundial a través de marcos conceptuales de las relaciones internacionales, en especial, del análisis racionalista de las negociaciones multilaterales. ${ }^{9}$

Después de sumergirse en el contenido y en la lógica que envuelve la adopción de esos textos, el artículo presenta las posturas de los Estados parte una vez adoptados los textos, para aclarar las razones de su difícil puesta en marcha y las interacciones entre Estados signatarios. Posteriormente se presenta el rol de

ron (Canadá) o no ratificaron (EE. UU.) la Convención de 1969. Dado que el artículo se centra en las posturas de los Estados del Sur, aquellas de EE. UU. y de Canadá en el marco de la negociación de los dos textos en cuestión o las posteriores a su adopción no se desarrollarán en el artículo.

${ }^{9}$ El institucionalismo sociológico hace énfasis en la importancia de los fenómenos de socialización, de las normas, valores y culturas compartidos en el seno de las organizaciones; se opone al institucionalismo racionalista, que hace énfasis en la importancia del cálculo costo/beneficio en el funcionamiento de las instituciones internacionales. Véase Robert O. Keohane, "International Institutions: Two Approaches”, International Studies Quaterly, vol. 32, núm. 4, 1988, pp. 379-396. 
los órganos de control examinando sus dinámicas de intercambio y de circulación con organizaciones globales y no gubernamentales. Estos análisis explican las consecuencias de la apropiación de los derechos humanos y la universalización de esos principios en las organizaciones regionales de los del "Sur", al mismo tiempo que contribuyen al debate sobre las interacciones entre formas globales y regionales de multilateralismo. ${ }^{10}$

\section{LA ADOPCIÓN DE INSTRUMENTOS DE PROTECCIÓN DE DERECHOS HUMANOS EN LOS ORGANISMOS REGIONALES DE LOS DEL "SUR": ENTRE ADAPTACIÓN Y OPOSICIÓN}

Varios trabajos se han enfocado en las motivaciones de la adopción de textos relativos a los derechos humanos, sobre todo en Estados cuyas prácticas están alejadas a priori de esos principios. En el contexto europeo, Moravcsik mostró una correlación entre la inestabilidad de una democracia y su propensión a firmar un texto capaz de fortalecer las instituciones. ${ }^{11}$ Para Hathaway, la decisión de comprometerse con un tratado internacional relativo a los derechos humanos está ligada a dos parámetros: la preexistencia de una aplicación interna de los principios y las consecuencias esperadas de la firma de un nuevo texto, en especial, las reacciones de los actores internos e internacionales. ${ }^{12}$ Entre más respetuoso

${ }^{10}$ Alan K. Henrikson, "The Growth of Regional Organizations and the Role of the United Nations", en Louise Fawcett y Andrew Hurrell (orgs.), Regionalism in World Politics. Regional Organization and International Order, Nueva York, Oxford University Press, 1995, pp. 122-169; Louise Fawcett, "Regionalism and Global Governance: An Appraisal”, en Pierre De Senarclens y Ali Kazancigil (orgs.), Regulating Globalisation: Critical Approaches to Global Governance, Nueva York, United Nations University Press, 2007, pp. 150-177; y Sebastian Raduletu, "Regional Human Rights Systems and the Principle of Universality", Revista de Stinte Politice, núm. 37-38, 2013, pp. 283-287.

11 Andrew Moravcsik, "The Origins of Human Rights Regimes: Democratic Delegation in Postwar Europe”, International Organization, vol. 54, núm. 2, 2000, pp. 217-252.

12 Oona A. Hathaway, "Why Do Countries Commit to Human Rights Treaties?”, Journal of Conflict Resolution, vol. 51, núm. 4, 2007, p. 93. 
de estos derechos sea, a priori, un Estado, más se verá incitado a firmar un texto juzgado de facto poco vinculante. La reflexión se fuerza hasta la paradoja: de entre los Estados donde esos derechos no son plenamente respetados, los más represores o cerrados son más proclives a firmar tales compromisos, habida cuenta de las pocas restricciones que conllevan, dada la ausencia de sanciones internacionales y de sociedad civil interna; la firma de un texto sin intención de respetarlo puede incluso significar que el régimen no está dispuesto a plegarse a las presiones de la sociedad civil. ${ }^{13} \mathrm{~A}$ la inversa, los Estados donde existe una forma de oposición política pueden temer que el reconocimiento de tales principios alimente las críticas internas.

En el marco de las organizaciones regionales que aquí nos interesan, se pueden añadir varias dimensiones a estos análisis. Adoptados después de la Declaración Universal de 1948 -con excepción de la Declaración Americana de los Derechos y Deberes del Hombre ${ }^{14}-$, los textos considerados en este artículo se analizan con la DUDH como referencia, ya sea para recordar los principios, para completarlos o para contradecirlos. Con una dimensión política clara, exponen la posición de sus redactores en el debate entre universalismo y regionalismo.

13 James R. Hollyer y Peter B. Rosendroff, "Why Do Authoritarian Regimes Sign the Convention Against Torture? Signaling, Domestic Politics and Non-compliance", Quarterly Journal of Political Science, vol. 6, 2011, pp. 275-327.

${ }^{14}$ Sobre la larga tradición latinoamericana de la reflexión sobre los derechos del hombre, véase Ellen L. Lutz y Kathryn Sikkink, "International Human Rights Law and Practice in Latin America”, International Organization, vol. 54, núm. 3, 2000, p. 639 et passim; Kathryn Sikkink, "Latin American Countries as Norm Protagonists of the Idea of International Human Right”, Global Governance, vol. 20, núm. 3, 2014, pp. 389-404; Laurence Burgorgue-Larsen, "El sistema interamericano de protección de los derechos humanos: entre clasicismo y creatividad", en Armin von Bogdandy, César Landa Arroyo y Mariela Morales Antoniazzi (orgs.), ¿̇Integración Suramericana a través del Derecho? Un análisis Interdisciplinario y Multifocal, Madrid, CEPC, 2009, pp. 241-260. 


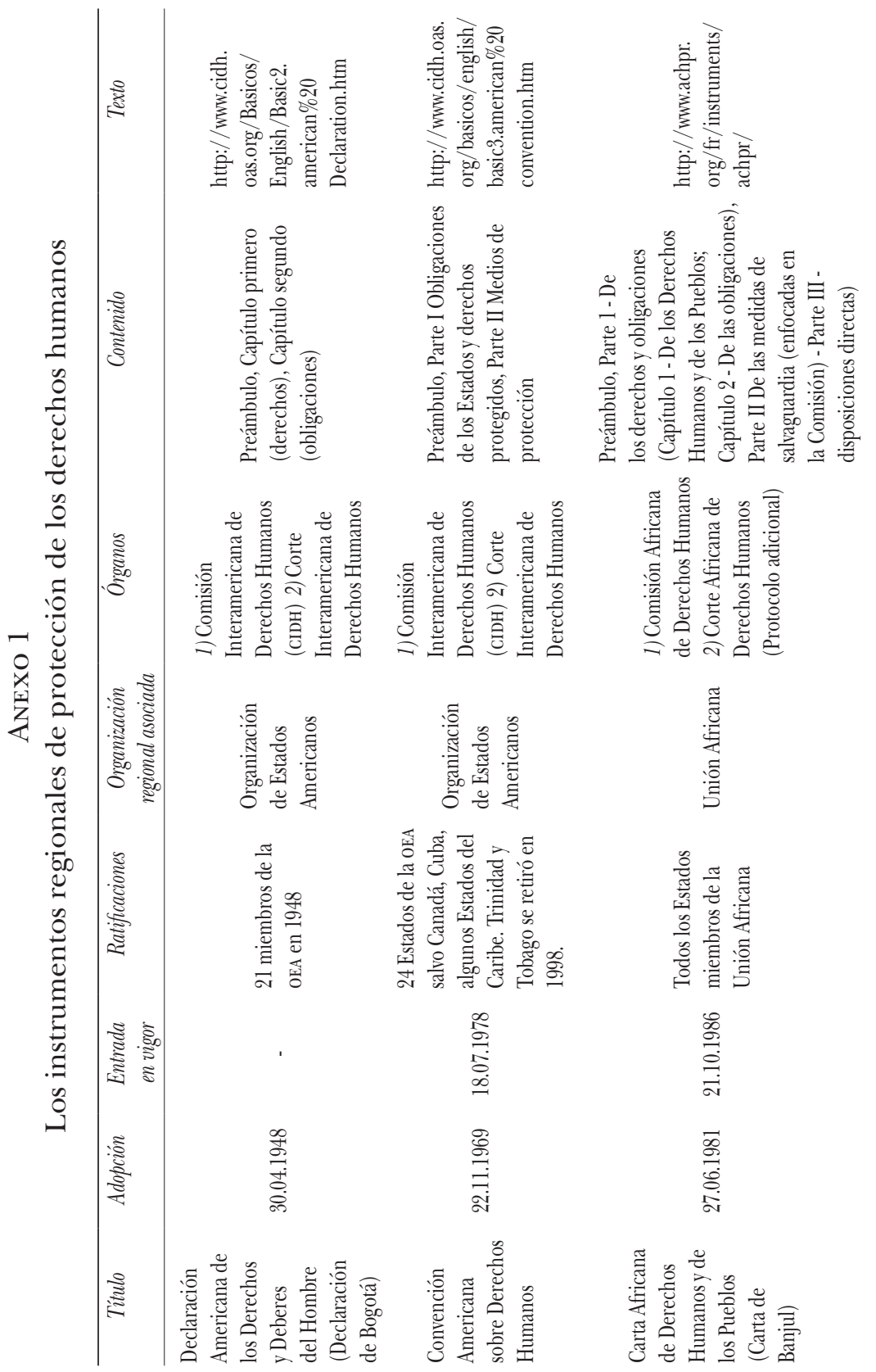



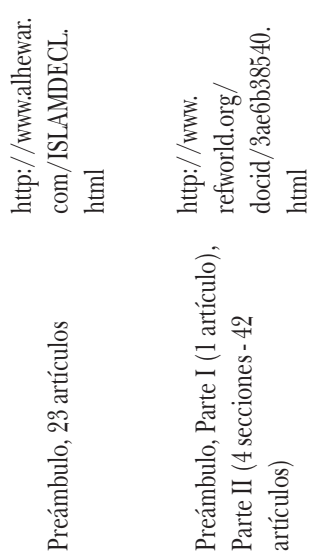

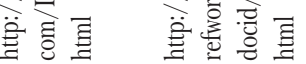

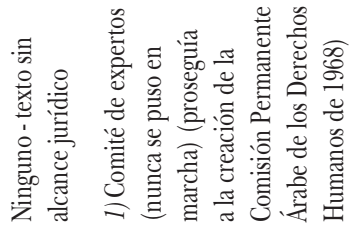

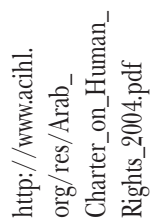

:

莺

关

in 造

葛

颉

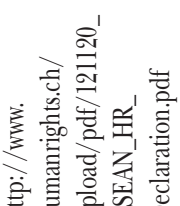

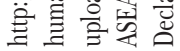

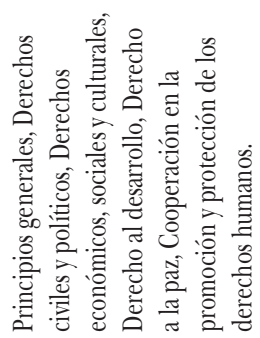

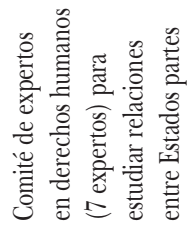
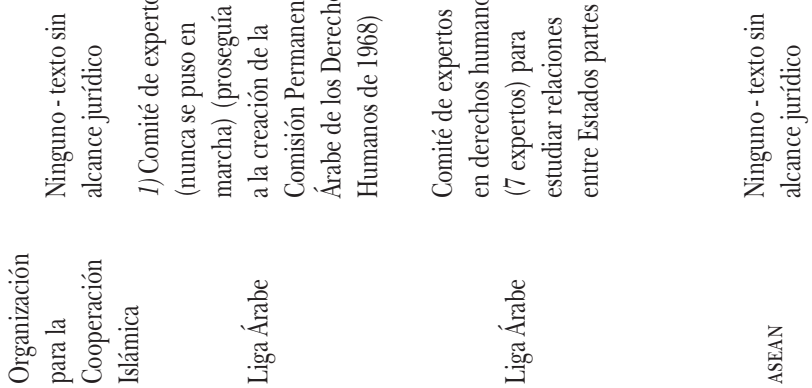

蒂

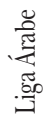

奀

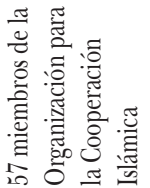

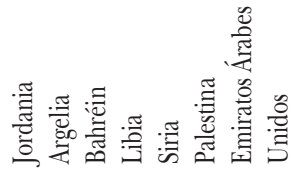
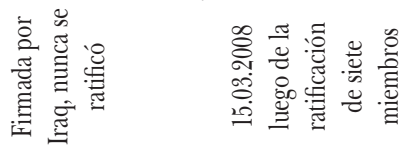

总

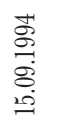

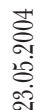

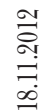
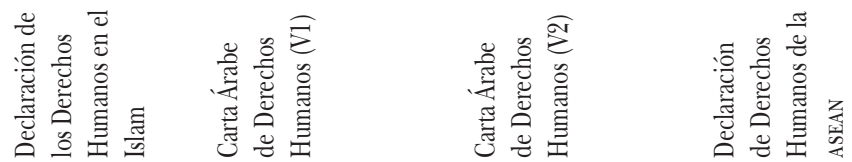
El análisis de las motivaciones que presiden la adopción de estos textos hace intervenir variables propias de los Estados en cuestión (su propensión a respetar los derechos humanos y a aceptar compromisos restrictivos, su grado de integración en el sistema internacional) y las reacciones esperadas luego de la firma de los textos, que pesan directamente sobre el contenido. La combinación de estos criterios hace emerger tres categorías de motivaciones: la voluntad de promover y fortalecer, a nivel regional, derechos concebidos como universales; la de conseguir retribuciones políticas, simbólicas o materiales; y, por último, una lógica diferencialista que consiste en afirmar una concepción regional para contrarrestar una supuesta dominación occidental sobre la definición de las normas. Conviene subrayar que estas motivaciones pueden combinarse o sucederse a pesar de cambios de régimen y de las relaciones de fuerzas internas o externas. Sobre todo, como se demostrará, la sola firma de un texto puede contribuir a transformar la relación de un Estado con los derechos humanos.

\subsection{Fortalecimiento y coexistencia con los principios universales: una crítica implícita al sistema internacional}

Una primera categoría de motivaciones corresponde a la voluntad de promover derechos considerados universales adaptándolos al marco regional, pero también estableciendo un precedente que pueda ser exportado hacia otras organizaciones regionales. Entre los primeros textos adoptados por Estados mayoritariamente del Sur, la Declaración Americana de los Derechos y Deberes del Hombre de 1948 y la Convención Americana sobre Derechos Humanos de 1969 respondían a esta lógica. Con ánimos de asentar las transiciones democráticas del continente americano y principalmente en América Latina, ${ }^{15}$ los fundadores del sistema interamericano de derechos humanos se esforzaron por transmitir

${ }^{15}$ Este aspecto político se manifiesta en que ambas cartas mencionadas hacen referencia a los derechos humanos, pero también a la importancia de una "sociedad democrática”. 
el espíritu de los textos de la onU en las fórmulas más completas según sus prioridades, pero sin adoptar una óptica diferencialista. El objetivo era también elaborar un sistema capaz de coexistir con la DUDH y los protocolos de la ONU, afirmando siempre la necesidad de una perspectiva regional "de acuerdo con las necesidades específicas de los países de este hemisferio. [...] Por consiguiente, la Convención Interamericana de Derechos Humanos deberá ser autónoma, y no complementaria, de los protocolos de Naciones Unidas". ${ }^{16}$ Igualmente, a través de la jurisprudencia de la Corte Interamericana de Derechos Humanos, que reivindica una concepción propia del universalismo jurídico, se estableció una doctrina específica para esta área regional y a la vez compatible con los textos internacionales.

El mismo dilema de coexistir con los textos internacionales se encuentra en los inspiradores de la Carta Árabe de Derechos Humanos, promovida desde los años sesenta en la Liga de Estados Árabes por los juristas de la Unión de Abogados Árabes. Defendiendo la adopción de un texto relativo a la protección de los derechos humanos en el contexto de Estados débilmente institucionalizados y a menudo poco respetuosos de esos principios, la ong más antigua de la región esperaba contribuir a su consolidación. ${ }^{17}$ Tras varias enmiendas, el espíritu inicial no logró transmitirse al texto adoptado en 1994 en la Liga Árabe, que, por el contrario, introducía límites a los derechos universales, estaba sometida a la ley islámica y no contaba con ningún órgano de control. ${ }^{18}$ Esta Carta, aunque nunca se ratificó, presenta el interés de poner en evidencia los principios universales privilegiados por los Estados árabes, que deben leerse bajo el prisma del rechazo a la presencia colonial: el derecho

16 Cecilia Cristina Naddeo, "The Inter-American System of Human Rights: A Research Guide”, GlobaLex, New York University Hauser Global Law School Program, septiembre 2010 y A. Glenn Mower Jr., Regional Human Rights: A Comparative Study of the West European and Inter-American Systems, Westport, Praeger, 1991, p. 44.

17 Mohammed Amin Al-Midani, Mathilde Cabinettes y Susan M. Akram (trads.), "Arab Charter on Human Rights 2004", Boston University International Law Journal, vol. 24, núm. 147, 2006, pp. 147-148.

18 Ahmed Mahiou, "La Charte arabe des droits de l'homme“, en Joël Andriantsimbazovina, Hélène Gaudin, Jean-Pierre Marguénaud, Stéphane Rials y Frédéric Sudre, Dictionnaire des droits de l'homme, París, Presses Universitaires de France, 2008, p. 19. 
de los pueblos de disponer de ellos mismos, ejercer control sobre sus recursos naturales, determinar la forma de sus estructuras políticas y perseguir libremente su desarrollo económico, social y cultural (artículo 2).

Si la interacción con los textos internacionales queda explícita en los casos mencionados, no se deberá concluir que estas iniciativas carecen de lógica crítica. Por una parte, las innovaciones de los países del Sur -que, fuera de los Estados de América Latina, todavía no habían conseguido la independencia al momento de la redacción de los textos de la ONU- permitieron alimentar la reflexión global sobre los derechos humanos. Por otra parte, la adopción de textos regionales en coexistencia con textos internacionales subraya los límites de éstos últimos y formula una crítica implícita al sistema internacional, el cual se juzga inoperante.

\subsection{La respuesta a las esperas internacionales o domésticas: una lógica de reivindicación o de retribución política}

La segunda categoría de motivaciones consiste en actuar en función de las incitaciones, dejando entrever una lógica de retribución o de liberación frente a las reivindicaciones y críticas de los actores que promueven los derechos humanos (sociedad civil interna o trasnacional, organizaciones internacionales, Estados socios). Estos actores forjan, en efecto, un marco político e institucional en el que la protección de los derechos humanos es objeto de fuertes incitaciones políticas, simbólicas o materiales, positivas (retribuciones) o negativas (sanciones). De esta forma, los textos se pueden tomar como un recurso político para los Estados que los ratifican. ${ }^{19}$ Esto puede considerarse vinculante, pues los textos adoptados pueden causar presiones para su ejecución, mientras que los compromisos, poco sólidos a priori, no se respetan.

Para los Estados represores, la lógica puede ser la del "blue washing", ${ }^{20}$ que consiste en demostrar una buena voluntad capaz

19 Oona A. Hathaway, op. cit.

20 Término proveniente de la investigación sobre responsabilidad social de 
de contribuir a su integración internacional. La demostración permite librarse -al menos temporalmente- de las críticas, ostentando una voluntad reformadora. ${ }^{21} \mathrm{El}$ carácter facultativo de tal proceder en el marco regional puede señalar un compromiso simbólico y favorecer la adopción de textos particularmente etéreos, en especial en las regiones donde la protección de los derechos humanos tiene lagunas en la mayoría de los Estados, como sucede en el Sudeste Asiático o en Medio Oriente.

No obstante, la efectividad de esta estrategia debe relativizarse, pues la adopción de esos instrumentos se expone a las críticas, sobre todo, externas. ${ }^{22}$ Organizaciones no gubernamentales regionales y organizaciones internacionales, aunque inicialmente hubieran apoyado la iniciativa, se opusieron a la primera versión de la Carta Árabe de Derechos Humanos, que nunca entró en vigor. ${ }^{23}$ En respuesta a sus críticas, el Alto Comisionado de los Derechos Humanos y la Comisión Árabe de Derechos Humanos llamaron a una revisión de la Carta, que desembocó en la nueva versión presentada en la Cumbre Árabe de Túnez el 23 de mayo de 2004. ${ }^{24}$ Para el Secretario General de la Liga Árabe y los expertos independientes que contribuyeron a la redacción del texto, se trataba de alinearlo más explícitamente al derecho internacional de los derechos humanos, a sabiendas de que la mayoría de los Estados miembros habían ratificado los tratados internacionales. Las modificaciones hechas en el transcurso del proceso del proyecto no permitieron llegar al fondo de esta lógica, pues la nueva Carta no instaura me-

las empresas, la noción de bluewashing hace referencia a las acciones "puestas en marcha para construir lazos visibles con Naciones Unidas (UN) para crearse una reputación positiva basada en el humanismo, con poco compromiso [real]". Para una definición más completa, véase W. Timothy Coombs y Sherry J. Holladay, Managing Corporate Social Responsibility: A Communication Approach, Chichester, Wiley-Blackwell, 2012, pp. 75-76.

${ }^{21}$ Oona A. Hathaway, "Do Human Rights Treaties Make a Difference?", Yale Law Journal, 2002 (Faculty Scholarship Series, Paper 839), pp. 1935-2042.

22 Oona A. Hathaway, 2007, op. cit.

23 Aldeeb Abu-Salieh, Les Musulmans Face aux Droits de l'Homme, Bochum, Winckler, 1994; y Ahmed Mahiou, op. cit.

24 Mohammed Amin Al-Midani, Mathilde Cabinettes y Susan M. Akram (trads.), 2006, op. cit. 
canismos de protección efectivos. ${ }^{25}$ Sin embargo, el texto aportó muchos avances: la Carta reconoce el carácter universal e indivisible de los derechos humanos, se refiere claramente a los instrumentos internacionales (artículo 2) y se añadieron disposiciones tras las críticas, en especial sobre la igualdad entre mujeres y hombres (artículos 1 y 3), los derechos de los niños (artículos 3 y 34) y de personas discapacitadas (artículo 40). Otras disposiciones siguen siendo problemáticas, lo que permite sobre todo adecuar la posición de ciertos Estados sobre los derechos de las mujeres y las minorías, la pena de muerte o incluso la libertad de expresión, de conciencia y de religión, que hacen eco de las reservas que los Estados árabes tienen sobre los instrumentos internacionales de protección de los derechos humanos.

El proceso de redacción de la Carta de Derechos Humanos de la ASEAn estuvo permeada de presiones similares. ${ }^{26}$ Mientras que los ministros de asuntos exteriores de la región apoyaban, desde 1993, la idea de un "mecanismo regional", la iniciativa no se concretó sino hasta la elaboración de la Carta de la ASEAn de 2007, cuyo artículo 14 prevé la puesta en marcha de una comisión intergubernamental de la ASEAn sobre los derechos humanos. Establecida en octubre de 2009, su misión fue redactar la Carta de Derechos Humanos de la asociación. Este proceso fue objeto de presiones por parte de los Estados menos dispuestos a adoptar mecanismos vinculantes, en especial Myanmar, Vietnam y Camboya. Además, tanto el Alto Comisionado de las Naciones Unidas para los Derechos Humanos (ACNUDH), Navi Pillay, como las ONG siguieron detenidamente el proceso y denunciaron que las negociaciones se estuvieran haciendo en secreto. El texto adoptado da cuenta de las tensiones entre Estados que ya habían integrado los derechos humanos a sus discursos de política exterior (Indonesia, Tailandia y, en menor medida, Filipinas, pretendían afirmar la referencia a los

${ }^{25}$ Sin embargo, se supone que un comité de expertos supervisa la aplicación. Merwat Rishmawi, "The Arab Charter on Human Rights", Carnegie Endowment for International Peace, 6 de octubre de 2009 (Sada, Middle East Analysis).

${ }^{26}$ Robin Ramcharan, “ASEAN's Human Rights Commission: Policy Considerations for Enhancing Its Capacity to Protect Human Rights”, University College London Human Rights Review, vol. 3, 2010, pp. 199-235. 
derechos universales) y un eje conservador que insistía en que se tomaran en cuenta las especificidades regionales ${ }^{27}$ y las leyes nacionales. ${ }^{28}$ Aunque el texto adoptado pareció decepcionante por estas ambigüedades, ${ }^{29}$ se trataba de insertarse en una dinámica global frente a las controversias sobre el respeto de los derechos humanos en la región. La ratificación de Myanmar permitió que las autoridades de ese país promovieran el proceso de transición política en 2008, a pesar de las dudas sobre su sinceridad. ${ }^{30}$ Aunque es muy pronto para analizar las consecuencias del texto, las críticas que provocó a nivel local permiten observar que, a pesar de su débil capacidad restrictiva, habrá contribuido a amplificar las presiones sobre sus signatarios más represores.

Más ampliamente, la lógica del blue washing da garantías de adhesión a los principios valorados por las organizaciones internacionales que brindan retribuciones simbólicas (reconocimiento), políticas (integración en los órganos de decisión) o materiales (ayuda o desarrollo). La Carta Africana de Derechos Humanos y de los Pueblos hace énfasis también en el derecho al desarrollo. De forma más clara, los protocolos adicionales sobre los derechos y el bienestar de los niños (1999) y sobre los derechos de las mujeres en África (2003) corresponden precisamente a las prioridades que mostraron las organizaciones internacionales en el continente. Esta convergencia no quedó sin subrayarse al momento de la adopción de los textos, evocando de forma inversa las prácticas de

${ }^{27}$ Forum Asia - Solidarity for Asian People's Advocacy Task Force on ASEAN and Human Rights (sapa TFAHr), "A Commission Shrouded in Secrecy - A Performance Report on the ASEAN Intergovernmental Commission on Human Rights 2010-2011”, 2012 (Informe); Working Group for an ASEAn Human Rights Mechanism, "CSOs call for transparent, participatory process in drafting HR Declaration”, Human Rights Herald, ASEANHrmech, abril 2012; Forum Asia, op. cit., p. 15.

28 Catherine Shanahan Renshaw, "The ASEAn Human Rights Declaration 2012”, Human Rights Law Review, vol. 13, núm. 3, 2013, pp. 557-579.

${ }^{29}$ No obstante, Gerard Clarke relativiza las críticas sobre el contexto en que se adoptó. Gerard Clarke, "The Evolving asean Human Rights System: The ASEAN Human Rights Declaration of 2012”, Northwestern Journal of International Human Rights, vol. 11, núm. 1, 2012, p. 27.

30 Tommy Thong Bee Koh, Rosario G. Manalo y Walter C. M. Woon (orgs.), The Making of the ASEAN Charter, Singapur, World Scientific Publishing, 2009. 
condicionamiento de la ayuda internacional para el respeto de los derechos humanos. ${ }^{31}$

Para terminar se menciona un efecto de desencadenamiento, incluso de contagio: con respecto, por ejemplo, a los Estados del Pacífico, la necesidad de alinearse al resto del mundo se evoca al promover la adopción de una Comisión de Derechos Humanos. ${ }^{32}$ En Asia del Sur se desarrolló un razonamiento similar: la ASACR (Asociación Sudasiática para la Cooperación Regional) es una de las pocas organizaciones regionales desprovistas de mecanismos de protección. ${ }^{33}$ Este argumento, aparejado a la importancia de los instrumentos capaces de ayudar a los ciudadanos a hacer valer sus derechos, subraya la influencia que ejerce la expansión de la regionalización de los derechos humanos, ante la cual parece cada vez más difícil sustraerse.

Cuando no viene acompañada de compromisos de los Estados parte y de una estrecha vigilancia por parte de organizaciones no gubernamentales y organizaciones internacionales, la lógica de retribución política incita a adoptar acuerdos que correspondan al mínimo denominador común de entre los Estados involucrados; lo esencial no es la efectividad de la protección, sino la muestra de valores compatibles con los de los actores de quienes se busca captar la atención.

1.3. La afirmación de especificidades regionales: del diferencialismo a un universalismo más incluyente

La redacción de ciertos textos sugiere una lógica de diferenciación, que se ha podido interpretar como una oposición ante el carácter universal de los derechos humanos. Conforme a la idea de la

31 Véase por ejemplo Gordon Crawford, "Foreign Aid and Political Conditionality: Issues of Effectiveness and Consistency", Democratization, vol. 4, núm. 3, 1997, pp. 69-108.

32 Imrana P. Jalal, "Why Do We Need a Pacific Regional Human Rights Commission?”, Victoria University Wellington Law Review, núm. 40, 2009, pp. 177-194.

${ }^{33}$ Forum Asia, "India: It Is Time for the Establishment of a South Asian Human Rights Mechanism”, 30 de agosto de 2014. 
relativa universalidad defendida por Donnelly, ${ }^{34}$ se trata de acompañar los principios universales de elementos propios a la identidad cultural regional y condicionarlos al respeto de la soberanía, tema sensible para los Estados del Sur. La soberanía y la identidad regional se valoran desde una crítica postcolonial, contra la idea de uniformización en torno a valores occidentales. Las posturas más críticas del universalismo tienden, sin embargo, a difuminarse a medida que crece la integración global de las preocupaciones de estos Estados.

Una inclinación diferencialista aparece en la lectura de la Carta Africana de Derechos Humanos y de los Pueblos. ${ }^{35}$ Privilegiando la importancia de la comunidad frente al individuo, valorado en la Declaración Universal, ${ }^{36}$ y afirmando la oposición de sus signatarios al colonialismo y al "neocolonialismo", refleja también la voluntad de sus redactores de mantener su independencia frente a los dos bloques de la Guerra Fría. ${ }^{37}$ Confiriéndole particular importancia a los derechos colectivos (económicos, sociales y culturales) frente a los individuales, el texto hace énfasis en la primacía del desarrollo frente a los derechos y libertades individuales, considerados "construcciones occidentales con una aplicabilidad limitada". ${ }^{38}$ La posibilidad de "derechos de recuperación" (clawback clauses), que permiten que los Estados parte no apliquen ciertas disposiciones, también constituye una concesión mayor de esta Carta al principio de soberanía. Sin embargo, como el preámbulo se basa en los textos internacionales en vigor, la vaga formulación de los derechos colectivos y de las condiciones que acompañan a los derechos de recuperación deja un margen de interpretación importante a

${ }^{34}$ Jack Donnelly, "Cultural Relativism and Universal Human Rights”, Human Rights Quarterly, vol. 6, núm. 4, 1984, pp. 400-419.

35 Kofi Oteng Kufuor, The African Human Rights System, Nueva York, Palgrave Macmillan, 2010, p.12.

${ }^{36}$ Sobre el contexto de adopción de la Carta Africana, véase Boniface Obinna Okere, "The Protection of Human Rights in Africa and the African Charter on Human and People's Rights: A Comparative Analysis with the European and American Systems", Human Rights Quarterly, vol. 6, núm. 2, 1984, p. 141-159.

${ }^{37}$ Boniface Obinna Okere, op. cit., p. 145.

${ }^{38}$ Kofi Oteng Kufuor, op. cit., p. 61. 
los órganos encargados de poner en práctica la Carta, susceptibles de moverse en el sentido de los principios universales.

La Declaración de los Derechos Humanos en el Islam, adoptada en la Organización de la Conferencia Islámica el 5 de agosto de 1990, puede considerase portadora de una lógica de oposición debido a sus incompatibilidades con los principios universales, a los que hace referencia y los subordina a la ley islámica (artículos 24 y 25). De cualquier forma, conviene señalar que si este texto, ratificado por 57 Estados, se inscribe contra la lógica de universalización en nombre, sobre todo, de la oposición al colonialismo (artículo 11), no se acompaña de un instrumento de control y ejerce una influencia limitada sobre sus signatarios, la mayoría de los cuales ha firmado otros documentos más cercanos a la DUDH.

Es más significativa la evolución de la Carta Árabe de Derechos Humanos. Mientras que la primera versión de 1994, concebida como diferencialista en pleno debate, ${ }^{39}$ había suscitado las críticas de organizaciones no gubernamentales y de la Comisión de Derechos Humanos de la onU debido a sus cláusulas incompatibles con la Declaración Universal, la versión revisada de 2004 menciona las particularidades culturales propias de los países árabes, pero se acerca más a los principios universales ${ }^{40}$ Sin designar a la "nación árabe" como elegida de Dios, recuerda en el preámbulo su importancia como cuna de las religiones, las civilizaciones, del saber y la sabiduría, para subrayar la continuidad entre este anclaje histórico y los derechos reconocidos. ${ }^{41}$ Determina además que ninguna de sus disposiciones debe interpretarse "de tal forma que se atente contra los derechos y libertades protegidos por las leyes internas de los Estados parte o enunciados en los instrumentos internacionales y regionales relativos a los derechos humanos que los Estados parte hayan adoptado o ratificado, incluidos los derechos de la

${ }^{39}$ La noción de "valores asiáticos" se había formulado como respuesta a la Conferencia de Viena de 1993.

40 Desde el punto de vista de los estándares internacionales, sigue siendo criticada por las ONG, juristas y defensores de los derechos humanos. Merat Rishmawi, "The Arab Charter on Human Rights and the League of Arab States: An Update", Human Rights Law Review, vol. 10, núm. 1, 2010, pp. 169-178.

${ }^{41}$ Ahmed Mahiou, op. cit., p. 8. 
mujer, de los niños y de las personas que pertenezcan a minorías" (artículo 43), una forma de anclar el compromiso con los principios universales, más allá de las particularidades del texto.

De manera similar, mientras que varios Estados del Sudeste Asiático defendían las especificidades de sus valores frente a los derechos universales asimilados a una visión occidental e individualista, ${ }^{42}$ la Declaración de Derechos Humanos de la ASEAN puso fin a este discurso. Bajo la influencia de los Estados más autoritarios de la región, este documento comporta ciertas fórmulas prudentes que hacen referencia a los "deberes", al contexto nacional y a la soberanía, para prevenir cualquier intento restrictivo. Las referencias a los derechos universales confirman, sin embargo, el desuso del argumento según el cual los valores asiáticos serían incompatibles con los derechos humanos, a los que ya no se descalifica como una construcción occidental impuesta ilegítimamente. La Declaración de la ASEAN consagra así la voluntad de ofrecer un valor agregado a los pueblos de la región, tomando en cuenta sus especificidades ${ }^{43}$ para enriquecer ciertas disposiciones de la DUDH. Este es especialmente el caso de las disposiciones consagradas a los derechos de las mujeres, de los niños y de los ancianos, de los discapacitados, los trabajadores migrantes y los grupos marginales y vulnerables (artículo 4), o incluso preocupaciones relativas al trabajo infantil, a las personas con enfermedades transmisibles y al derecho a la salud reproductiva. El texto innova también al evocar "derechos de solidaridad", que incluyen el derecho a un medio ambiente sano, limpio y duradero, el derecho al desarrollo y a la paz, desde el centro de las preocupaciones de la ASEAN y sus miembros. Para este texto, como para los precedentes, interviene además la posibilidad de otra interpretación del principio de soberanía: ésta puede concebirse no

42 Esta idea la promovieron especialmente Singapur y Malasia. Theodore Wm. de Bary, Asian Values and Human Rights: a Confucian Communitarian Perspective, Cambridge, Harvard University Press, 1998; James C. Hsiung, Human Rights in East Asia: A Cultural Perspective, Nueva York, Parangon Publishers, 1986 y Anthony J. Langlois, The Politics of Justice and Human Rights: Southeast Asia and Universalist Theory, Cambridge, University Press, 2001.

${ }^{43}$ Catherine Shanahan Renshaw, op. cit., p. 559. 
como una limitación de los derechos evocados, sino como un compromiso para ponerlos en práctica.

La idea de los derechos diferenciados tiende, por lo tanto, a disolverse en las referencias a los derechos universales, cuya sustancia puede seguir presentando oposición, pero sus principios ya no. Las especificidades de los textos observados permiten, al contrario, identificar una base de derechos reconocidos por doquier: derecho a la vida, prohibición de recurrir a la tortura o a tratos degradantes, derecho a la libertad y a la seguridad, prohibición de la esclavitud, derecho al asilo, a la propiedad, a la libertad de expresión, de opinión y de reunión, o incluso derecho a la justicia y derechos sociales y culturales como el trabajo, la salud, la seguridad social, la educación y la libertad sindical. A la inversa, la lógica de diferenciación o de oposición, que tenía sentido en un mundo donde los derechos humanos eran vistos desde una perspectiva estrictamente descendiente que consistía en promover, en el Sur, textos redactados por los Estados del Norte, corresponde cada vez en menor medida a la realidad. De hecho, conforme los derechos promovidos en textos de organizaciones del Sur se van tomando en cuenta a nivel mundial, ${ }^{44}$ y conforme los procesos de consulta dirigidos por las organizaciones internacionales se van extendiendo, se desarrolla, a la par, un enfoque más interactivo.

\section{LAS POSTURAS ESTATALES FRENTE A LA GENERALIZACIÓN DE LA REFERENCIA DE LOS DERECHOS HUMANOS}

Una vez adoptados los textos, los comportamientos de sus signatarios varían según la importancia acordada a cada instrumento y las consecuencias que de ahí se esperan. La tipología de Albert O.

${ }^{44}$ En especial el respeto a los pueblos indígenas, los derechos de los niños y de los homosexuales, en los textos interamericanos; el lugar de la familia y los derechos de las minorías, en la Carta Árabe de 2004 (a pesar de los límites que permiten a los gobiernos relativizar la aplicación de esos derechos); el derecho a la autodeterminación de los pueblos, a la libre disposición de las riquezas y recursos naturales, a la eliminación de la explotación económica extranjera, así como el derecho al trabajo, a la salud y a la educación, en la Carta Africana. 
Hirschman ${ }^{45}$ ofrece una posible lectura sobre las posturas de los Estados parte, particularmente en caso de desfase entre lo esperado y los principios efectivamente puestos en marcha. Aplicables frente a los socios en el seno de coaliciones ad hoc o institucionalizadas, ${ }^{46}$ las opciones que evoca Hirschman ante una situación de insatisfacción son la salida (exit, que consiste en renunciar a la relación) o la toma de la palabra (voice) para expresar una insatisfacción, una elección ampliamente determinada por el grado de apego del individuo con la organización y su voluntad de cooperar para reformarla (loyalty). Completada con la noción de negligencia (neglect), que corresponde a un comportamiento pasivo en espera de la erosión de la organización, ${ }^{47}$ esta tipología permite caracterizar las posturas de los Estados en el marco de los instrumentos regionales de protección de los derechos humanos.

La diversidad de los textos e instrumentos regionales permite a los actores, en efecto, referirse a ejemplos alternativos. Además, la salida es más probable en el nivel regional que en el global, pues, dados los relativamente difusos contornos de las regiones, no es imposible imaginar la afiliación a otro grupo o la formación de una organización alternativa; los subconjuntos regionales también presionan por la ejecución de los derechos humanos.

Así, se dibuja una correlación entre las posturas de los Estados parte y el costo de su incorporación a los instrumentos regionales de protección de los derechos humanos (grado de respeto a esos derechos al momento de la adhesión y carácter más o menos restrictivo

45 Albert O. Hirschman, Exit, Voice, and Loyalty: Responses to Decline in Firms, Organizations, and States, Cambridge, Harvard University Press, 1970.

${ }^{46}$ Sobre la transposición del marco conceptual de Hirschman en el marco del análisis de las políticas exteriores, véase principalmente Frédéric Charillon, $L a$ France peut-elle encore agir sur le monde?, París, Armand Colin, 2010; Josepha Laroche (org.), La loyauté dans les relations internationales, París, L'Harmattan, 2011; y Delphine Lagrange, "La política de Francia y el conflicto Árabe-Israelí: una relación entre cuatro. Los efectos de la guerra en Iraq en la diplomacia francesa en Oriente próximo”, Foro Internacional, vol. 49, núm. 4, 2009, pp. 748-769.

${ }^{47}$ Caryl E. Rusbult, Isabella M. Zembrodt y Lawanna K. Gunn, "Exit, Voice, Loyalty, and Neglect: Responses to Dissatisfaction in Romantic Involvements", Journal of Personality and Social Psychology, vol. 43, núm. 6, 1982, pp. 1230-1242. 
de los textos); el grado de integración regional e internacional de los Estados involucrados (posición central o marginal en el seno de los sistemas regional e internacional); y la retribución esperada del apego a los principios o de la oposición a ellos (en términos materiales y simbólicos, internos y externos).

\subsection{La adhesión a los derechos humanos: ¿ una postura de potencias medias?}

Intentando determinar los parámetros favorables para una postura de lealtad, varios trabajos sobre las "potencias medias" hacen de la adhesión al multilateralismo y a los derechos humanos un rasgo recurrente de la postura internacional de estos Estados, definidos por su poder relativo, pero también por sus comportamientos y las normas de sus políticas exteriores. ${ }^{48}$ Este rasgo sería válido en el marco regional, donde las potencias medias estarían dispuestas a promover principios de cooperación que les permitan traspasar los límites del juego clásico. Sin embargo, al observar que esta definición de la acción internacional de las potencias medias excluye a aquellas que tengan posturas contestatarias, en especial cuando pertenecen al Sur, Ping demostró que la probabilidad de que un Estado actúe conforme a los valores del multilateralismo o de derechos humanos depende de su propensión a hibridar esos valores con los de su propio sistema político: ${ }^{49}$ entre más alto sea el costo de la hibridación, menor será la probabilidad de actuar como buen alumno del multilateralismo; y la probabilidad de desplegar una diplomacia contestataria se refuerza.

48 Andrew F. Cooper (org.), Niche Diplomacy: Middle Powers After the Cold War, Londres, Macmillan, 1997; y Andrew F. Cooper, Richard A. Higgott y Kim R. Nossal (orgs.), Relocating Middle Powers: Australia and Canada in a Changing World Order, Vancouver, UBC Press, 1993. Cooper expone cuatro elementos de definición del poder medio: el tamaño, la posición relativa, las normas promovidas y el comportamiento en la escena internacional.

${ }^{49}$ Se propone, por lo tanto, una definición a la vez estadística, normativa (percepción externa y autopercepción) y política ( statecraft) de la potencia media. Jonathan H. Ping, Middle Power Statecraft: Indonesia, Malaysia and the Asia Pacific, Farnham, Ashgate, 2005. 
En el seno de las organizaciones regionales del Sur, los Estados más proclives a adecuarse a los instrumentos relativos a la protección de los derechos humanos son aquellos que cumplen con ambas características: potencia media y valores cercanos a los enunciados por los textos, que se convierten en un recurso para difundir sus modelos. En el ejemplo Sudasiático, los Estados que intentaron hacer más incluyente la Declaración de la ASEAn fueron aquellos cuyos derechos y libertades son de los más respetados en la región: Indonesia, Tailandia y Filipinas, cuyos respectivos pesos en el seno de la organización pueden considerarse equivalentes y que, además, están a favor de una mayor integración regional. El compromiso con los derechos humanos y la lealtad a los textos que los protegen se presenta aquí como una función de la integración de los Estados en sus sistemas regionales, pero también, correlativamente, en el sistema internacional: esta observación apoya la idea según la cual los textos regionales tienden a difundir los principios universales más que a particularizarlos.

\subsection{La crítica y la salida, opciones relativamente poco explotadas}

Para los Estados cuyos gobiernos se oponen a la puesta en práctica o a la formulación de los textos adoptados en el marco regional, la opción entre expresar un desacuerdo (voice) o la salida (exit) está en función de la libertad de acción que permiten los textos.

La expresión de un desacuerdo puede ser interna o externa. La externa consiste en rechazar los principios o los propios textos para negarse a su adopción, alegando que las normas universales no son aplicables a los contextos particulares. La tendencia va hacia el desvanecimiento de este tipo de oposición; la postura de desacuerdo interno es la dominante. La expresión interna consiste en que los Estados intentan reformar a posteriori los textos a los cuales se sumaron para volverlos más operantes, modificar ciertos principios o denunciar sus disfunciones. Estas tentativas permiten promover ciertos elementos de la agenda internacional de los gobiernos involucrados, se trate ya de una dimensión más protectora (Indonesia en la ASEAN), o ya de la denuncia de una implementación de los 
derechos humanos (los miembros de la Alianza Bolivariana para los Pueblos de Nuestra América, ALbA, en la Organización de Estados Americanos).

No obstante, es interesante observar que los instrumentos regionales, cuando su carácter trasciende la simple declaración de intención, pueden ocasionalmente hacer que los miembros tengan problemas con sus propias posturas en la arena mundial. Se observa, entonces, una contradicción entre posturas simbólicas y prácticas efectivas: este fue especialmente el caso del Brasil de Dilma Rousseff, a quien la Comisión Interamericana de Derechos Humanos criticó en abril de 2011 por no haber consultado lo suficiente a las poblaciones locales antes de autorizar la construcción de la represa de Belo Monte. ${ }^{50}$ El gobierno retiró a su embajador y congeló sus contribuciones financieras a la Comisión y a la OEA, sin llegar a retirarse. Esta presión contribuyó a abrir el debate sobre la reforma de la organización, actualmente dirigida tras el escudo de un "grupo de trabajo especial" que organiza amplias consultas con las onG y el público. ${ }^{51}$

Más marginales, las estrategias de salida permiten observar la posibilidad de formar agrupaciones alternativas. En la práctica, la salida generalmente se evoca bajo la forma de amenaza, como en la reunión anual del 4-5 de julio de 2012 en Bolivia, donde Ecuador, Bolivia, Venezuela y Nicaragua amenazaron con dejar la oEA si no había reforma. ${ }^{52}$ Las salidas efectivas las usan los gobiernos habituados a llevar una diplomacia contestataria, para quienes salir tiene un bajo costo pues el "zarpazo" es un elemento constitutivo de su política exterior. ${ }^{53}$ Después de Trinidad y Tobago en 1998, está

50 "Brazil Breaks Relations with Human Rights Commission Over Belo Monte Dam”, Latin America News Dispatch, 3 de mayo de 2011.

${ }^{51}$ International Justice Resource Center (IJRC), "Understanding the IACHR Reform Process", IRJC, 20 noviembre 2012; Organización de los Estados Americanos, "Public consultation on the draft Reforms of the Rules of Procedure, policies and practices of the Inter-American Commission on Human Rights", 15 de febrero de 2013 (versión revisada).

${ }^{52} \mathrm{Al}$ mismo tiempo, Brasil y Perú llamaron otra vez a la reforma, pero sin amenaza directa de dejar la Comisión.

${ }^{53}$ Bertrand Badie, Le diplomate et l'intrus. L'entrée des sociétés dans l'arène internationale, París, Fayard, 2008. 
el caso de Venezuela: el presidente Hugo Chávez anunció el 10 de septiembre de 2012 que denunciaba a la Convención Interamericana de los Derechos Humanos y que dejaba la Corte (cuya ratificación universal había sostenido previamente), por haber sido objeto de críticas sobre la puesta en práctica de los derechos humanos. ${ }^{54}$ Conforme al artículo 78 de la Carta, esta salida siguió al fracaso de una campaña que pretendía entorpecer la autoridad de la Comisión, a la que Venezuela acusaba de actuar "bajo las órdenes de Estados Unidos". ${ }^{55}$ Después de haber condicionado las visitas de la Comisión a exigencias inadmisibles, ${ }^{56}$ el gobierno de Chávez optó por la estrategia de salida. Sin embargo, cabe señalar que un movimiento tal no significa la denuncia total del sistema interamericano de derechos humanos, pues el Estado no se retiró formalmente del sistema de protección de los derechos humanos de la OEA: como la Comisión también se encarga de supervisar la puesta en práctica de los tratados de la oEA, aún puede atender las

${ }^{54}$ Esta decisión tuvo como consecuencia que se limitara el acceso de los ciudadanos venezolanos a la Corte Interamericana de Derechos Humanos después del 10 de septiembre de 2013. Resulta interesante, sin embargo, que Venezuela siga siendo miembro del ACNUDH.

55 Associated Press, "Venezuela's Government Begins Process of Withdrawing From oAs Human Rights Bodies", The Washington Post, 10 de septiembre de 2012. La crítica sobre el carácter sesgado de la comisión había empezado luego de que ésta reconociera (aunque criticando los riesgos de violación de los derechos humanos y la democracia, y condenando la violencia) al gobierno que había tomado el poder temporalmente tras el golpe de Estado de abril de 2002.

${ }^{56}$ Principalmente que la Comisión "reconociera públicamente su error" con respecto al golpe de Estado del 11 de abril de 2002, que cambiara a un secretario ejecutivo y nombrara a un nuevo relator para Venezuela, y que reformara las reglas de los procedimientos para garantizar "la transparencia, la independencia y la pluralidad de pensamiento en el centro del sistema para la protección de los derechos humanos". International Justice Resource Center (IJRC), "Venezuela Denounces American Convention on Human Rights as IACHR Faces Reform”, 19 de septiembre de 2012; Inter-American Commission on Human Rights (IACHR), "Venezuela", en IACHR Annual Report 2013, 2013, pp. 497-599; Parlement Européen, "European Parliament resolution of 24 May 2012 on the possible withdrawal of Venezuela from the Inter-American Commission on Human Rights", 24 de mayo de 2012. 
quejas sobre violaciones de la Declaración Americana de los Derechos y Deberes del Hombre. ${ }^{57}$

Este rechazo reforzó la voluntad de consolidar la alternativa que constituye la ALBA, producto de la voluntad política de los Estados que reivindican una orientación de izquierda radical en América Latina. La alternativa propuesta no denuncia, sin embargo, las referencias a los derechos humanos, más bien los aprovecha para condenar las prácticas de los gobiernos acusados de imperialismo: ${ }^{58}$ sólo queda condenada la interpretación "politizada" o "prooccidental" de los derechos. ${ }^{59}$

\section{3. ¿Generalización de la negligencia?}

Más allá de las estrategias mencionadas, la adoptada con más frecuencia es, finalmente, la negligencia. ${ }^{60}$ Una primera forma de llevar a cabo esta postura es la adopción de reservas de interpretación, que permiten ratificar una carta vaciándola de sustancia, volviéndola inoperante o más conforme a los principios que los Estados no lograron imponer en las negociaciones. Así, la Carta

${ }^{57}$ Perú había intentado retirarse en 1999 de la jurisdicción contenciosa de la Corte Interamericana para evitar un juicio sobre el caso de los tres jueces constitucionales destituidos por no apoyar un nuevo mandato del presidente Fujimori. Se rechazó el retiro debido a que la Convención Americana no permite que un Estado se sustraiga únicamente de la Corte; las autoridades peruanas habían renunciado al retiro total. Véase Jo M. Pasqualucci, The Practice and Procedure of the Inter-American Court of Human Rights, Cambridge, University Press, 2003, p. 116; e International Court of Human Rights, "Case of the Constitutional Court v. Peru", Sentencia del 24 de septiembre de 1999 (Competencia).

58 Por ejemplo: la Alianza Bolivariana para los Pueblos de Nuestra América (ALBA), "South American and Caribbean Countries Call on US to Respect Human Rights of Africans in Ferguson", Uhurunews.com, 20 de agosto de 2014; "The Bolivarian Alliance for the Peoples of our America (ALBA), "The ALBA Condemns Israeli Attacks on Gaza", Alba Infos, 13 de julio de 2014.

${ }^{59}$ Roy Chaderton, embajador de Venezuela ante la OEA calificó la IAcHR "de instrumento del Imperio [los Estados Unidos], incluyendo cómplices y pusilánimes", en "Human Rights in the Americas. Chipping at the Foundations", The Economist, 9 de junio de 2012.

${ }^{60}$ Caryl E. Rusbult, Isabella M. Zembrodt y Lawanna K. Gunn, op. cit. 
Árabe de 2004 precisa que todo Estado puede adoptar reservas sobre los artículos "siempre y cuando la reserva no entre en conflicto con los objetivos fundamentales de la Carta" (artículo 53.1), aunque éstos últimos no quedan precisados. La Carta Africana de Derechos Humanos y de los Pueblos presenta dos tipos de "reservas y declaraciones". Las de Egipto vuelven inoperantes ciertos principios pues someten a la ley islámica las disposiciones sobre la libertad de conciencia y de religión (artículo 8); eliminan lo relativo a la discriminación contra las mujeres y la protección de los derechos de las mujeres y los niños (artículo 18.3). A la inversa, las reservas y declaraciones que añadieron Sudáfrica y Zambia dan cuenta de la decepción de sus negociadores frente a la falta de alcance del texto. Sudáfrica precisa que deberían organizarse consultas para reforzar los mecanismos de aplicación de la Carta, aclarar los criterios capaces de limitar los derechos y libertades que garantiza, y alinearse a las resoluciones de la ONU con respecto a la caracterización del sionismo. Finalmente, Zambia precisa su interpretación de los artículos 13 (igualdad de acceso de los ciudadanos a los bienes públicos) y 37 (designación de miembros de la Comisión Africana de Derechos Humanos y de los Pueblos), y añade una provisión que estipula que todos los miembros de la Organización para la Unidad Africana (convertida en la Unión Africana en 2002) deberían someter a la Comisión los informes sobre sus prácticas.

La negligencia también puede convertirse en una estrategia consciente de los Estados que se adhieren a los textos bajo una perspectiva de blue washing. Entre menos restrictivos sean los instrumentos, mayores son las probabilidades de que se incorporen Estados cuya perspectiva es la negligencia. El orden de afiliaciones a la Carta de la ASEAN es interesante a este respecto: Singapur, Brunéi y Laos, seguidos de Malasia, Vietnam, Camboya y Myanmar, es decir, los Estados de la región donde la puesta en práctica de los derechos humanos es más deficiente, fueron los primeros en ratificar la Carta. Los gobiernos de Filipinas, Indonesia y Tailandia, al contrario, la ratificaron al final, luego de intensos debates sobre el débil alcance del texto. 
Estas observaciones permiten considerar que varios Estados se suman únicamente porque podrán adoptar una postura negligente. Esta categoría de la tipología está extendida: no sólo hace referencia a los actores que recurren a la negligencia por decepción, sino que puede constituir una condición sine qua non de su adhesión.

Por lo tanto, queda claro que la postura de negligencia es la que se ha vuelto dominante con la multiplicación de textos, pero también por la rutinización de la falta de medios (logísticos, humanos, financieros, jurídicos) que entorpece su consecución. Esta tendencia podría dejar ver que los derechos humanos están más desatendidos entre más se generalizan a escala mundial a través de instrumentos poco vinculantes; se banaliza así la referencia sin darle cuerpo. La realidad, sin embargo, es más compleja. Aunque la cuestión de la universalidad se haya vuelto obsoleta con la generalización de su uso como referencia, regresa sobre el contenido de los textos regionales por medio de críticas de organizaciones internacionales globales (en especial el Consejo de Derechos Humanos de la ONU) y de organizaciones no gubernamentales, pero sobre todo debido al papel principal de los órganos de control. Los textos brindan, en efecto, un recurso a esos actores que, incluso en ausencia de métodos de acción vinculantes, son depositarios de la interpretación de los textos y pueden pronunciarse sobre sus aplicaciones regionales y locales.

\section{El CONTROL y la EVOluCión de LOS INSTRUMENTOS REGIONALES DE PROTECGIÓN DE DERECHOS HUMANOS}

Lejos de ceñirse a un papel de foro donde se confrontan estrategias estatales, los órganos de control se caracterizan por tener cierta autonomía, intereses propios y características sociológicas específicas. ${ }^{61}$ No se conforman con ser receptores de las normas globales,

${ }^{61}$ Sobre las organizaciones internacionales como actores de puesta en práctica, véase Jutta Joachim, Bob Reinalda y Bertjan Verbeek (orgs.), International Organizations and Implementation: Enforcers, Managers, Authorities?, Londres, Rout- 
sino que participan en su difusión y definición. ${ }^{62}$ Examinar las dinámicas de circulación y de difusión de las normas internacionales de protección de los derechos humanos implica una triple perspectiva, jurídica, política y sociológica. El estudio del papel que juega el poder judicial que requiere la movilización de un cuerpo jurídico ha sido objeto de trabajos específicos y queda fuera del marco de este artículo. ${ }^{63}$ Esta última parte analizará las dos últimas perspectivas: las características sociológicas de los actores que compiten por la difusión y los intercambios de normas, cuestionando sus relaciones de poder. Tras una presentación de las características del papel de estos órganos, se analiza en qué medida logran formar un lugar de intercambio y de circulación normativa entre las organizaciones regionales y globales.

\subsection{Los órganos de control: papel e influencia}

Si los instrumentos regionales de protección de los derechos humanos pueden resultar poco vinculantes, su alcance toma otra amplitud cuando van acompañados de órganos de control. Estos últimos descansan sobre esquemas organizacionales comunes; a menudo siguen el modelo de los órganos internacionales de protección de derechos humanos (anexo 2). ${ }^{64}$

ledge, 2008. Sobre la corriente sociológica en relaciones internacionales, véase Guillaume Devin, Sociologie des relations internationales, París, La Découverte, 2013.

${ }^{62}$ Bagayoko-Penone y Bernard Hours (orgs.), États, ong et production de normes sécuritaires dans les pays du Sud, París, L'Harmattan, 2011; Martha Finnemore y Kathrin Sikkink, "International Norm Dynamics and Political Change", International Organization, vol. 52, núm. 4, 1998, pp. 887-917; Ann Florini, "The Evolution of International Norms”, International Studies Quaterly, vol. 40, núm. 3, pp. 363-389; e Yves Schemeil y Wolf-Dieter Eberwein, Normer le monde, París, L'Harmattan, 2009.

${ }^{63}$ Para un estudio detallado de los factores jurídicos, véase Sandrine Turgis, Les interactions entre les normes internationales relatives aux droits de la personne, París, Pedone, 2012.

${ }^{64}$ Dos instrumentos no prevén la creación de órganos dedicados a la puesta en práctica: la Declaración de los Derechos Humanos en el Islam y la Declaración de Derechos Humanos de la AsEAN. 


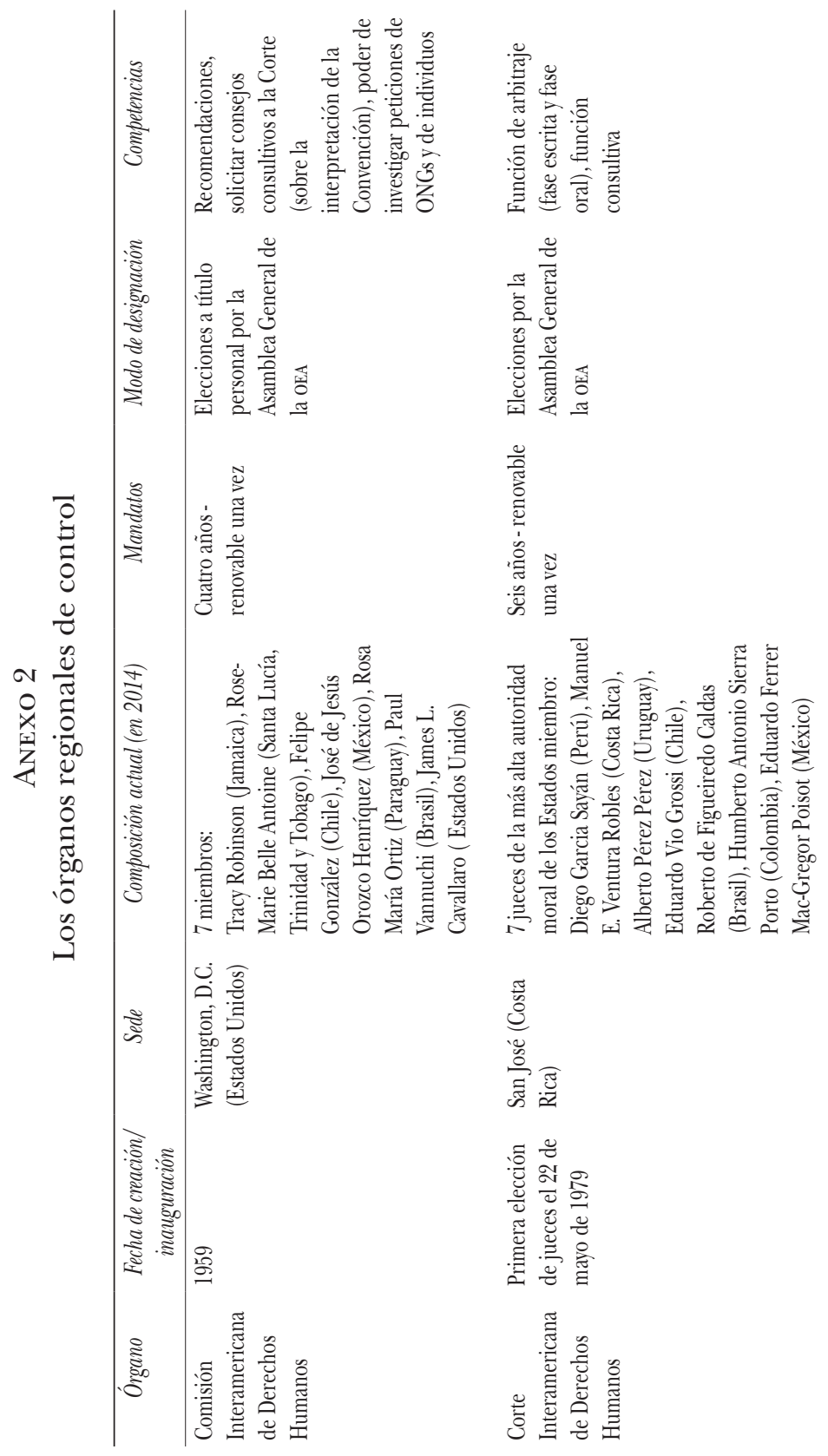



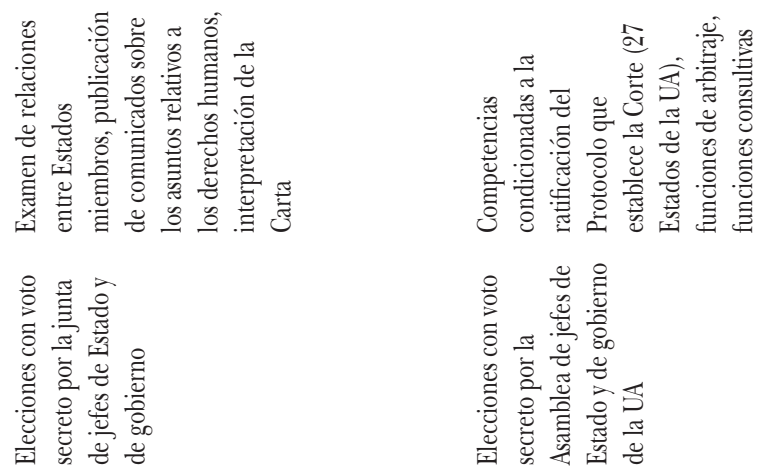

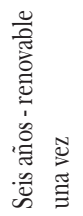
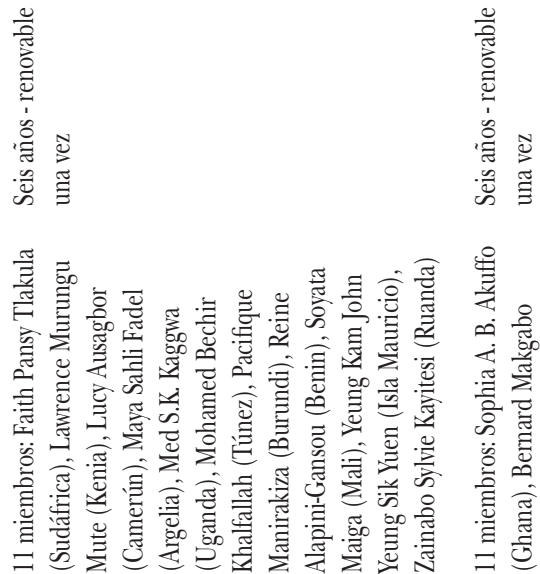

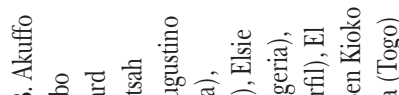

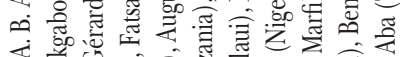

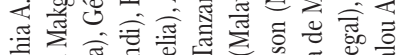

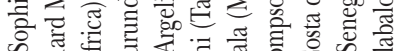

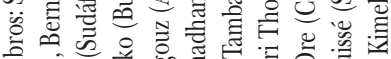

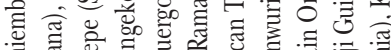

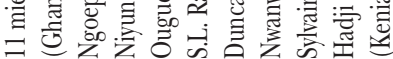

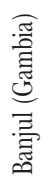

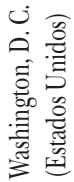

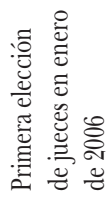

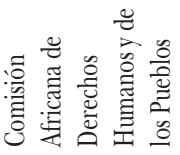

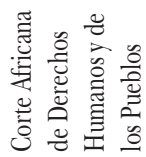


Estos órganos se reparten a lo largo de un continuum que va de un papel de experiencia y consulta a competencias judiciales o cuasijudiciales. La competencia del comité de expertos en derechos humanos de la Carta Árabe se limita al examen de los informes de los Estados parte, mientras que la Comisión Africana de Derechos Humanos y de los Pueblos dispone de competencia cuasijudicial. Sus comisionados están encargados de interpretar las disposiciones de la Carta, tarea que a menudo conciben de forma extensiva con miras a fortalecer la protección de los derechos mencionados. Así, con frecuencia han restringido considerablemente la interpretación de los derechos de salida, alterando la jurisprudencia internacional para prevenir todo comportamiento negligente de los Estados signatarios. ${ }^{65}$ La evolución de la composición y del papel de la Comisión también denota que se empiezan a tomar en cuenta los estándares internacionales. Así, en 1987, todos los comisionados eran hombres, y la mayoría mantenía fuertes vínculos con su gobierno de origen. ${ }^{66}$ Desde 2005, la Comisión, bajo el auspicio de la Unión Africana, desarrolló criterios con miras a garantizar la independencia de los comisionados y una mejor paridad entre las candidaturas propuestas por los Estados miembros. Para noviembre de 2010, la evolución era sorprendente: la Comisión tenía seis mujeres y cinco hombres, cuyos vínculos con sus gobiernos respectivos eran más débiles que en el pasado. Además, la Comisión designó relatores sobre asuntos cada vez más variados y sensibles, como las cárceles y las condiciones de detención, los derechos de las mujeres, la libertad de expresión y el acceso a la información, los defensores de los derechos humanos y los refugiados, los que solicitan asilo, los migrantes y desplazados dentro de sus países. La Comisión también estableció grupos de trabajo sobre varias preocupaciones propias de los Estados africanos, en especial los pueblos y los comités indígenas, los derechos económicos y sociales, la tortura, la pena de muerte, los ancianos y disca-

${ }^{65}$ Kofi Oten Kufuor, op. cit.

66 Magnus Killander, "The African Commission on Human and People's Rights", en Manisuli Ssenyonjo, The African Human Rights Regional System, Leiden/ Boston, Martinus Nijhoff Publishers, 2012, p. 236. 
pacitados, e incluso las industrias extractivas. Además, se crearon otros comités consultivos para la protección de los derechos de las personas con VIH/SIDA y de las que están en riesgo de contraer la enfermedad. ${ }^{67}$

Sorprende constatar que, en el caso del continente africano, la protección de los derechos humanos se concibió de una forma cada vez más extensiva y vinculante. Así, la Carta Africana se completó con un protocolo adicional para la creación de una Corte Africana de Derechos Humanos y de los Pueblos, concebida para fortalecer la acción de la Comisión y garantizar el estatus judicial de la protección de los derechos humanos en el continente. La jurisdicción de esta corte se ejerce hoy sobre quince Estados de la Unión Africana. ${ }^{68}$

Otro órgano regional, la Corte Interamericana de Derechos Humanos, con sus fallos, ha dotado al continente americano de una jurisdicción propia, resueltamente centrada en la defensa de los derechos de los individuos. ${ }^{69}$ Este órgano está inmerso en la concepción particular de los derechos humanos de la región, pues se puede decir que es una jurisprudencia original, vanguardista e incluso, a veces, "jurídicamente no conformista". ${ }^{70}$ Se trata de una especificidad que asumió la Corte, que pudo haber ofendido a ciertos Estados miembros, ${ }^{71}$ y se ilustra con cinco conceptos: la subjetivización del derecho interamericano, su penalización, su constitucionalización, su humanización y su moralización. ${ }^{72}$ Como en el caso africano, los trabajos de la Corte se preparan mediante aquellos de la Comisión Interamericana de Derechos Humanos,

${ }^{67}$ Magnus Killander, op. cit., p.241.

68 Como esta corte es de reciente creación, todavía resulta delicado analizar los efectos producidos por su jurisprudencia naciente.

${ }^{69}$ Ludovic Hennebel y Hélène Tigroudja (orgs.), Le particularisme interaméricain des droits de l'Homme. En l'honneur du 40e anniversaire de la Convention américaine des droits de l'homme, París, Editions Pédone, 2009, pp. 75-121.

${ }^{70}$ Ludovic Hennebel, "La cour interaméricaine des droits de l'Homme: entre particularisme et universalisme", en Ludovic Hennebel y Hélène Tigroudja, $o p$. cit., p. 78.

${ }^{71}$ Loc. cit.

72 Para un análisis detallado de las características de la jurisprudencia de la Corte Interamericana, véase Ludovic Hennebel, op. cit. 
encargada de recoger peticiones y de dar consejos consultivos a la Corte. La independencia de sus miembros está garantizada, pues la nominación se efectúa a título personal.

Como actores, sus órganos tienen un papel considerable en la elaboración de una jurisprudencia percibida como meramente regional. Este poder se refuerza con el carácter a menudo débil de las disposiciones de las Cartas, particularmente cuando presentan reservas de interpretación. ${ }^{73}$ Jueces y comisionados han ido definiendo una protección cada vez más extensiva, poniéndole un alto a las tentativas de los Estados parte de esquivar sus obligaciones. De ahí surge una pregunta: ¿qué factores pueden explicar que algunos Estados, poco proclives a permitir que se limite su soberanía en nombre de la protección de los derechos humanos, permitan que surjan órganos dotados de tales competencias? La función de foro que ejercen estos órganos, que permite el intercambio y la circulación de normas entre actores de concepciones diversas, y actúa en la esfera global, regional o no gubernamental, constituye un elemento para la respuesta.

\subsection{Las ONG y los comisionados, actores que llevan normas al centro de la circulación entre organizaciones regionales y globales}

Los lazos y circulaciones entre actores regionales y globales son estrechos. Conviene de inicio mencionar la especificidad de la Unión Africana a este respecto. Contrario a las otras organizaciones regionales, la Unión Africana se presenta explícitamente como el relevo de la onu en el continente. Las referencias a las normas globales son particularmente frecuentes en las comunicaciones de la Comisión Africana de Derechos Humanos y de los Pueblos. ${ }^{74}$ Más allá de este caso particular, la mayoría de los instrumentos regionales establecen una relación entre normas globales, regionales y nacionales. El artículo 43 de la Carta Árabe de Derechos Humanos es

${ }^{73}$ Kofi Oteng Kufuor, op. cit.

${ }^{74}$ Magnus Killander, op. cit., p. 235. 
particularmente revelador de esta tensión, ${ }^{75}$ pues enuncia una cierta jerarquía entre estándares nacionales, regionales y globales, dando supremacía a los globales sobre las legislaciones nacionales. ${ }^{76}$ Para el conjunto de los textos estudiados, las referencias frecuentes a las normas globales permiten proponer que la circulación de normas se hace antes que nada en beneficio de una concepción universalista. Para los Estados, el hecho de desarrollar instrumentos regionales de protección de derechos humanos vuelve a exponerse a las críticas de los órganos globales, a menudo secundados por las organizaciones no gubernamentales, expertos o comunidades académicas.

Por lo tanto, hay que ver la evolución de los dispositivos regionales bajo el ángulo de esas presiones e interacciones. El primer caso revelador de esas dinámicas: el contexto de redacción de la Convención Interamericana de Derechos Humanos muestra claramente una interacción con Naciones Unidas, pues volvió a crecer gracias al proceso de redacción de los dos Pactos de 1966, el conflicto potencial entre los dos regímenes que incitaban a la oEA a no terminar su proyecto antes de que sus miembros hubieran tenido la oportunidad de renovar su compromiso con la adopción de un tratado regional sobre los derechos humanos. El ejemplo de la Carta Árabe de Derechos Humanos ilustra asimismo la importancia de las interacciones, pues su segunda versión integró ciertas críticas que habían acompañado a la primera versión de la Carta. La Comisión Árabe sobre los Derechos Humanos se hizo cargo de las críticas, provenientes de expertos, organizaciones no gubernamentales y la comunidad académica, pues invitó a los Estados de la Liga Árabe a transmitir sus observaciones y propuestas para hacer evolucionar al texto. Al mismo tiempo, el Alto Comisionado para los Derechos Humanos tomó esta oportunidad para reunir en El Cairo, en diciembre de 2003, a varios expertos para discutir propuestas de mejoras. La nueva versión, adoptada en la cumbre de

${ }^{75}$ Mohamed Y. Mattar, “Article 43 of the Arab Charter of Human Rights: Reconciling National, Regional and International Standards", Harvard Human Rights Journal, vol. 26, p. 91.

${ }^{76}$ Mohamed y Mattar, op. cit., pp. 92-93. 
Túnez el 23 de mayo de 2004, está más en consonancia con los estándares internacionales. ${ }^{77}$

Este importante papel de las ONG se encuentra en las oportunidades de impulsar y difundir normas a nivel internacional. También se las ha calificado como emprendedoras de normas, término más ampliamente aplicable a todo actor que deliberada y activamente promueve una o varias normas. ${ }^{78}$ Estos emprendedores pueden también emplear medios desviados, como en el contexto de la redacción de la Declaración de los Derechos Humanos de la ASEAN: actuando en conjunto con el ACNUDH, las ONG consiguieron peso en el proceso gracias a los representantes que voluntariamente dejaron filtrar información clave, como el proyecto que propuso Myanmar o los argumentos de los Estados más conservadores. ${ }^{79}$

Al percatarse del gran papel que jugaron las ONG, los órganos de control muy pronto decidieron integrarlas a su trabajo. En especial, la Comisión Africana de Derechos Humanos y de los Pueblos organiza consultas regulares con la sociedad civil de los Estados signatarios. Cada sesión está precedida por una reunión de organizaciones no gubernamentales africanas e internacionales que participan en la preparación de las reuniones de la Comisión. La mayoría de los comisionados contribuyen activamente en estos foros, donde no solamente hay intercambio de ideas, sino también de influencia. En mayo de 2010, por ejemplo, el foro de las ONG adopta 23 resoluciones, de las cuales cuatro se retomaron directamente en las resoluciones de la Comisión. Las ONG pueden además acceder al estatus de observadores, lo que les permite hacer propuestas en las sesiones. Este estatus es también indispensable para que las ONG puedan llevar casos ante la Corte Africana. ${ }^{80}$ La Comisión Interamericana de Derechos Humanos también dispone de lazos privilegiados con organizaciones no gubernamentales e individuos, que pueden presentar peticiones y solicitar audiencias. En el Sudeste Asiático, el nuevo compromiso de la ASEAN en materia de derechos humanos

77 Loc. cit.

78 Margaret E. Keck y Kathrin Sikkink, Activits Beyond Borders: Advocacy Networks in International Politics, Ithaca, Cornell University Press, 1998.

${ }^{79}$ Gerard Clarke, op. cit., pp. 15-16.

${ }^{80}$ Magnus Killander, op. cit. 
dio origen a lo que puede calificarse de track-three diplomacy, que designa a las dinámicas de intercambio entre organismos de la ONU, la ASEAN y organizaciones no gubernamentales regionales. Estos cambios permitieron que en la década de 2000 entraran a la agenda nuevas temáticas, sobre todo en torno a cuestiones de seguridad humana. ${ }^{81}$

Sin embargo, estos lazos no podrían dar cuenta solos de las dinámicas de interacción normativa. Un análisis de la formación y de las trayectorias de los miembros de los órganos de control ${ }^{82}$ confirma la existencia de trayectorias profesionales que atraviesan experiencias globales, regionales, no gubernamentales y, a veces, académicas. Así, la mayoría de los comisionados de los órganos del Sur se formaron en el seno de universidades estadounidenses y europeas. Este es el caso, por ejemplo, de James L. Cavallaro y Faith Pansy Tlakula, de Harvard; de Tracy Robinson, que estudió en Oxford; e incluso de Sahli Fadel Maya y Soyata Maiga, de la Escuela Nacional de la Magistratura francesa. Algunos desempeñan actividades académicas, como Pacifique Manirakiza, profesor de la Universidad de Ottawa. Las trayectorias profesionales de estos comisionados frecuentemente se acentúan, además, con la militancia en la esfera no gubernamental. Su reputación a menudo se vincula con un pasado de activismo, como los de Faith Pansy Tlakula (militante de los derechos de las mujeres) y Soyata Maîga (fundadora de la Coordinación de asociaciones y de organizaciones no gubernamentales feministas en Mali). En fin, los recorridos dan cuenta, en su mayoría, de experiencias en agencias u organismos de la onU, aunque este perfil sigue estando más extendido en

${ }^{81}$ Robin Ramcharan, “AsEan's Human Rights Commission: Policy Considerations for Enhancing Its Capacity to Protect Human Rights”, University College London Human Rights Review, vol. 3, 2010, p. 203.

${ }^{82}$ La recopilación de datos biográficos sobre los miembros de los órganos que ponen en marcha instrumentos regionales de protección de derechos humanos es a veces delicada. Aquí el dilema fue identificar trayectorias particulares que no permiten sacar conclusiones generales sobre los perfiles sociológicos de los miembros de dichos órganos. La elección de concentrarse en los comisionados se justifica por el hecho de que las comisiones preparan el trabajo de las cortes, conque juegan un papel importante en la preparación de sus decisiones. 
los miembros de la Comisión Interamericana que en sus contrapartes africanas.

Estas trayectorias pesan sobre la forma en que los comisionados preparan los expedientes. Si sus trayectorias sociológicas no bastan para explicar las dinámicas de circulación entre organizaciones regionales y globales, dan cuenta de los estrechos lazos entre los dos niveles. Aparejados al papel principal de los órganos que ponen en práctica la interpretación de los textos y los intercambios regulares que desarrollan con las esferas no gubernamental y global, estos lazos fomentan la universalización de los derechos humanos. Este análisis aclara la cuestión de la universalización pues refleja un doble movimiento: de lo global a lo regional, pero también, y sobre todo, de lo regional a lo global; por lo tanto, desde el Sur a lo global.

\section{CONCLUSión}

Este artículo, al proponer un análisis cruzado de los instrumentos regionales de protección de los derechos humanos y de su control, aclara la contribución de los Estados del Sur en las transformaciones multilaterales por medio de las interacciones entre regionalismo y universalismo.

Se muestra en primer lugar que el proceso de redacción de los textos regionales ha estado marcado por un triple dilema de afirmar las especificidades regionales, oponerse a la influencia del Norte sobre los debates normativos e introducir una base de derechos universales. Aunque la puesta en práctica de estos instrumentos en los Estados esté dominada por posturas de negligencia, su adopción misma es significativa. Por una parte, contribuye al surgimiento de nuevas normas globales relativas a los derechos humanos; por otra, a dotar a los instrumentos regionales de órganos de control que interactúen con organizaciones no gubernamentales y organizaciones universales; así, los Estados se someten también a las miradas y críticas externas.

Una triple dinámica de circulación parece entonces llevar a una universalización en torno a normas cada vez más incluyentes: 
circulación descendente que permite difundir los principios y prácticas valoradas por las organizaciones universales; circulación ascendente que ve remontar las preocupaciones que introducen las organizaciones regionales del Sur, cada vez tomadas más en cuenta a escala mundial; por último, circulación horizontal, que ve difundirse los principios y prácticas entre las organizaciones regionales del Sur. Lejos de estar condenados a sufrir u oponerse a la influencia de las normas globales, estas organizaciones contribuyen a una universalización más incluyente.

\section{Traducción de Ana InÉs Fernández Ayala}

\section{Bibliografía}

Al-Midani, Mohammed Amin, Cabinettes, Mathilde y Susan M. Akram (trads.), "Arab Charter on Human Rights 2004", Boston University International Law Journal, vol. 24, núm. 147, 2006, pp. 147-164.

Badie, Bertrand, Le diplomate et l'intrus. L'entrée des sociétés dans l'arène internationale, París, Fayard, 2008

Bagayoko-Penone, Niagalé y Bernard Hours (orgs.), États, ong et production de normes sécuritaires dans les pays du Sud, París, L'Harmattan, 2011.

Burgorgue-Larsen, Laurence, "El sistema interamericano de protección de los derechos humanos: entre clasicismo y creatividad", en Armin von Bogdandy, César Landa Arroyo y Mariela Morales Antoniazzi (orgs.), ¿Integración Suramericana a través del Derecho? Un análisis Interdisciplinario y Multifocal, Madrid, CEPC, 2009, pp. 241-260.

Charillon, Frédéric, La France peut-elle encore agir sur le monde?, París, Armand Colin, 2010.

Clarke, Gerard, "The Evolving asean Human Rights System: The asEan Human Rights Declaration of 2012", Northwestern Journal of International Human Rights, vol. 11, núm. 1, 2012.

Coombs, Timothy W. y Sherry J. Holladay, Managing Corporate Social Responsibility. A Communication Approach, Chichester, Wiley-Blackwell, 2012. 
Cooper, Andrew F. (org.), Niche Diplomacy: Middle Powers After the Cold War, Londres, Macmillan, 1997.

Cooper, Andrew F., Higgott, Richard A. y Kim R. Nossal (orgs.), Relocating Middle Powers: Australia and Canada in a Changing World Order, Vancouver, UBC Press, 1993.

Crawford, Gordon, "Foreign Aid and Political Conditionality: Issues of Effectiveness and Consistency", Democratization, vol. 4, núm. 3, 1997, pp. 69-108.

De Bary, Théodore Wm., Asian Values and Human Rights: A Confucian Communitarian Perspective, Cambridge, Harvard University Press, 1998.

Devin, Guillaume, Sociologie des relations internationales, París, La Découverte, 2013.

Donnelly, Jack, "International Human Rights: a Regime Analysis", International Organization, vol. 40, núm. 3, 1986, pp. 599-642.

Donnelly, Jack, "Cultural Relativism and Universal Human Rights", Human Rights Quarterly, vol. 6, núm. 4, 1984, pp. 400-419.

Fawcett, Louise, "Regionalism and Global Governance : An Appraisal", en Pierre De Senarclens y Ali Kazancigil (orgs.), Regulating Globalisation: Critical Approaches to Global Governance, Nueva York, United Nations University Press, 2007, pp. 150-177.

Finnemore, Martha y Kathrin Sikkink, "International Norm Dynamics and Political Change", International Organization, vol. 52, núm. 4, 1998, pp. 887-917.

Florini, Ann, "The Evolution of International Norms", International Studies Quaterly, vol. 40, núm. 3, pp. 363-389.

Forum Asia - Solidarity for Asian People's Advocacy Task Force on ASEAN and Human Rights (SAPa Tfahr), "A Commission Shrouded in Secrecy - A Performance Report on the ASEAN Intergovernmental Commission on Human Rights 2010-2011”, 2012 (Informe).

Goheneix, Alice (org.), "Une opinion publique internationale?", Raisons Politiques, vol. 3, núm. 19, número especial, 2005.

Greer, Steven, The European Convention on Human Rights: Achievements, Problems and Prospects, Cambridge, University Press, 2006.

Hathaway, Oona A., "Do Human Rights Treaties Make a Difference?", Yale Law Journal, 2002, pp. 1935-2042 (Faculty Scholarship Series, Paper 839). -, "Why Do Countries Commit to Human Rights Treaties?", Journal of Conflict Resolution, vol. 51, núm. 4, 2007, pp. 588-621. 
Hennebel, Ludovic y Hélène Tigroudja (dirs.), Le particularisme inter-américain des droits de l'Homme. En l'honneur du 40e anniversaire de la Convention américaine des droits de l’homme, París, Editions Pédone, 2009.

Henrikson, Alan K., "The Growth of Regional Organizations and the Role of the United Nations", en Louise Fawcett y Andrew Hurrell (orgs.), Regionalism in World Politics: Regional Organization and International Order, Nueva York, Oxford University Press, 1995, pp. 122-169.

Hirschman, Albert O., Exit, Voice, and Loyalty: Responses to Decline in Firms, Organizations, and States, Cambridge, Harvard University Press, 1970.

Hollyer, James R. y Peter B. Rosendorff, "Why Do Authoritarian Regimes Sign the Convention Against Torture? Signaling, Domestic Politics and Non-Compliance", Quarterly Journal of Political Science, vol. 6, 2011, pp. 275-327.

Hsiung, James C., Human Rights in East Asia: A Cultural Perspective, Nueva York, Parangon Publishers, 1986.

Jalal, Imrana P., "Why Do We Need a Pacific Regional Human Rights Commission?”, Victoria University Wevlington Law Review, núm. 40, 2009, pp. 177-194.

Joachim, Jutta, Bob Reinalda y Bertjan Verbeek (orgs), International Organizations and Implementation : Enforcers, Managers, Authorities?, Londres, Routledge, 2008.

Keck, Margaret E. y Sikkink, Kathrin, Activits Beyond Borders: Advocacy Networks in International Politics, Ithaca, Cornell University Press, 1998.

Keohane, Robert O., "International Institutions: Two approaches”, International Studies Quaterly, vol. 32, núm. 4, 1988, pp. 379-396.

Killander, Magnus y Christof Heyns (orgs.), Recueil de Documents Clés de l'Union Africaine Relatifs aux Droits de l'Homme, Pretoria, University Law Press (PUlP), 2013.

Killander, Magnus, "The African Commission on Human and People's Rights", en Manisuli Ssenyonjo, The African Human Rights Regional System, Leiden/Boston, Martinus Nijhoff Publishers, 2012, pp. 235-248.

Koh, Tommy Thong Bee, Manalo, Rosario G. y Walter C. M. Woon (orgs.), The Making of the ASEAN Charter, Singapur, World Scientific Publishing, 2009.

Lagrange, Delphine, "La política de Francia y el conflicto Árabe-Israelí: una relación entre cuatro. Los efectos de la guerra en Iraq en la di- 
plomacia francesa en Oriente próximo", Foro Internacional, vol. 49, núm. 4, 2009, pp. 748-769.

Langlois, Anthony J., The Politics of Justice and Human Rights: Southeast Asia and Universalist Theory, Cambridge, University Press, 2001.

Laroche, Josepha (org.), La loyauté dans les relations internationales, París, L'Harmattan, 2011.

Lutz, Ellen L. y Kathryn Sikkink, "International Human Rights Law and Practice in Latin America”, International Organization, vol. 54, núm. 3, 2000, pp. 633-659.

Mahiou, Ahmed, "La Charte arabe des droits de l'homme", en Joël Andriantsimbazovina, Hélène Gaudin, Jean-Pierre Marguénaud, Stéphane Rials y Frédéric Sudre, Dictionnaire des droits de l'homme, París, Presses Universitaires de France, 2008, pp. 124-127.

Moravcsik, Andrew, "The Origins of Human Rights Regimes: Democratic Delegation in Postwar Europe”, International Organization, vol. 54, núm. 2, 2000, pp. 217-252.

Mower, Glenn Jr., Regional Human Rights: A Comparative Study of the West European and Inter-American Systems, Westport, Praeger, 1991.

Naddeo, Cecilia Cristina, "The Inter-American System of Human Rights: A Research Guide”, GlobaLex, Nex York University Hauser Global Law School Program, septiembre de 2010.

Obinna Okere, Boniface, "The Protection of Human Rights in Africa and the African Charter on Human and People's Rights: A Comparative Analysis with the European and American Systems", Human Rights Quarterly, vol. 6, núm. 2, 1984, pp. 141-159.

Office of the High Commissioner for Human Rights y International Bar Association, "Chapter 3. The Major Regional Human Rights Instruments and the Mechanisms for Their Implementation", en Human Rights in the Administration of Justice: A Manual on Human Rights for Judges, Prosecutors and Lawyers, United Nations, Nueva York, 2003, pp. 71-111.

Oteng Kufuor, Kofi, The African Human Rights System, Nueva York, Palgrave Macmillan, 2010.

Pasqualucci, Jo M., The Practice and Procedure of the Inter-American Court of Human Rights, Cambridge, University Press, 2003.

Ping, Jonathan H., Middle Power Statecraft: Indonesia, Malaysia and the Asia Pacific, Farnham, Ashgate, 2005. 
Raduletu, Sebastian, "Regional Human Rights Systems and the Principle of Universality”, Revista de Stinte Politice, núm. 37-38, 2013, pp. 283-287.

Ramcharan, Robin, “AsEAN's Human Rights Commission: Policy Considerations for Enancing Its Capacity to Protect Human Rights”, University College London Human Rights Review, vol. 3, 2010, pp. 199-235.

Rishmawi, Merat, "The Arab Charter on Human Rights and the League of Arab States: An Update", Human Rights Law Review, vol. 10, núm. 1, 2010, pp. 169-178.

Rishmawi, Merwat, "The Arab Charter on Human Rights”, Carnegie Endowment for International Peace, 6 de octubre de 2009 (Sada, Middle East Analysis).

Rusbult, Caryl E., Isabella M. Zembrodt y Lawanna K. Gunn, "Exit, Voice, Loyalty, and Neglect: Responses to Dissatisfaction in Romantic Involvements", Journal of Personality and Social Psychology, vol. 43, núm. 6, 1982, pp. 1230-1242.

Schemeil, Yves y Wolf-Dieter Eberwein, Normer le monde, París, L'Harmattan, 2009.

Shanahan Renshaw, Catherine, "The ASEAn Human Rights Declaration 2012”, Human Rights Law Review, vol. 13, núm. 3, 2013, pp. 557-579.

Shelton, Dinah, "The Promise of Regional Human Rights Systems", en Burns H. Weston y Stephen P. Marks (orgs.), The Future of International Human Rights, Leiden, Brill, 1999, pp. 351-356.

Sikkink, Kathryn, "Latin American Countries as Norm Protagonists of the Idea of International Human Right”, Global Governance, vol. 20, núm. 3, 2014, pp. 389-404.

Simmons, Beth A., Mobilizing for Human Rights: International Law in Domestic Politics, Cambridge, University Press, 2009.

Tardu, Maxime, "Le Nouveau Conseil des Droits de l'Homme aux Nations Unies: Décadence ou Résurrection?”, Revue Trimestrielle des Droits de l’Homme, núm. 72, 2007, pp. 967-991.

Turgis, Sandrine, Les interactions entre les normes internationales relatives aux droits de la personne, París, Editions Pedone, 2012.

Wegmann, Simonne, "Regional Human Rights Systems: a Comparative Analysis", Green Lab, núm. 1, Geneva Laboratory of Political Science, 2011. 